\title{
An Experience of Taiwan Policy Development To Accelerate Cloud Migration
}

\author{
Sheng-Chi Chen \\ Department of Management Information Systems, \\ National Chengchi University \\ Taipei, Taiwan
}

\begin{abstract}
Developing cloud computing is a key policy for government, while convenient service is an important issue for people living. In the beginning of 2010, the Taiwan Government has launched a "Cloud Computing Development Project", and has devoted to service planning and investment activities. At the end of 2012, in a three-year comprehensive review and suggestion adoption from public and private sectors, the Taiwan Government adjusted the policy and rename as "Cloud Computing Application and Development Project".
\end{abstract}

From the perspectives of government application, industry development, and cloud open platform, this study describes how the vision drive goals and thinking push forward strategies. In the process of government and industry collaboration, it is progressively created value for cloud services. The Cloud Computing Project Management Office acts a key role as policy advisor, matching platform, and technical supporting to the achievements of (1) policy assessment and strategy enhancement; (2) construction of cloud open platform to the demand and supply linkage; (3) innovation and integration planning for government service application, leading to industry development.

Keywords-Cloud Computing; Action Research; Project Management Office

\section{INTRODUCTION}

The development of the cloud computing industry re-shapes the global IT industry. Cloud computing technology and its service applications are taking off around the world. To seize the initiative and ensure future competitive advantages in the cloud computing market, Taiwan is adapting its currentlyestablished hardware manufacturing foundation and extending it to its IT industry. The Cloud Computing Development Project, initiated by the Taiwan government in early 2009, includes 15 cloud computing projects. After three years of effort, by the end of 2012, the proposals were revised to accommodate the diversity of domestic demand and technological competition from international industries. The cloud applications by the government shall be transparent to the general public and shall lead the way for the cloud computing industry's development in Taiwan. The cloud platform, named Cloud Open Lab, is offered as a supplydemand channel in between governmental agencies and the hardware/software vendors in cloud computing applications. Generally speaking, additional governmental procurement projects for hardware equipment are not recommended. Furthermore, an evaluation policy for the government cloud computing project is provided, for "Value to citizens" and
"Economy to the industry" as the planning and implementation target guidelines. At the same time, the Cloud Computing Development Project has been revised to become the Cloud Computing Application and Development Project. This research discusses how the two cloud computing projects successively lead to accelerate cloud migration of the ICT development in Taiwan.

\section{RELATED WORKS}

\section{A. Cloud Computing}

Gartner pointed out that cloud computing is a computational mode that is large-scale and provides IT capabilities, to be accessed by multiple external users over the Internet [2][5]. The National Institute of Standards and Technology (NIST) defines: "Cloud computing is a model for enabling ubiquitous, convenient, on-demand network access to a shared pool of configurable computing resources that can be rapidly provisioned and released with minimal management effort or service provider interaction." The NIST definition lists five essential characteristics of cloud computing: on-demand self-service, broad network access, resource pooling, rapid elasticity or expansion, and measured service. It also lists four "deployment models" (private, community, public and hybrid) that together categorize ways to deliver cloud services, and three "service models": Software as a Service (SaaS), Platform as a Service (PaaS), and Infrastructure as a Service (IaaS) [4][8].

\section{B. Government Policy}

Cloud computing has been regarded as one of the crucial industries in Taiwan. With cloud computing having gradually emerged as the mainstream of future ICT applications, the governments of advanced economies throughout the world have been working actively to formulate strategies for cloud computing development. Government agencies will be able to benefit from cloud computing to improve efficiency and reduce costs, further upgrading and restructuring the industry services with core competitiveness to drive market growth in both domestic demand and export sales. The U.S., which already possesses a substantial cloud computing industry, has been focusing on enhancing government efficiency and reducing costs; the European Union (EU) and South Korea have made the development of overseas export markets the main focus of their cloud computing strategies, while Japan has positioned cloud computing as a key tool for strengthening the competitiveness of the Japanese ICT sector. Common features seen in many of the cloud computing development policies 
formulated by these various governments include the use of cloud computing as a foundation for developing mobile services that provide an improved user experience, creating value through open access to data, formulating relevant standards and regulations, simplifying government procurement procedures, and utilizing big data analysis techniques to help improve government performance and promote commercial development [1].

\section{Industry Development}

Google and Amazon.com are the two leaders in the development of global cloud computing applications. Google started out as a web search service and branched out to e-mail, online video, maps, social networking, and various online software services. Amazon.com's core business is in ecommerce, selling books over the Internet, and then expanded to multimedia, software, electronics, and household items. This created a new business model with indicative significance for the cloud computing services. Google and Amazon.com are based on the Internet and software services, starting out by providing software as a service (SaaS) and then scaling up their business with large-scale data centers to provide computing resources such as platform as a service (PaaS) and infrastructure as a service (IaaS). They are the leaders in cloud computing services. Major global players such as Microsoft, IBM, VMware, AT\&T, and Apple have also developed their own cloud computing services to further drive innovation into the emerging cloud applications [1].

\section{RESEARCH METHOD}

Action research refers to research where the participant solves an immediate problem with active participation in the situation whilst conducting research for the solution, thereby improving the working efficiency [3] [7]. Action research allows the researcher to observe and describe the conditions in a practical work setting, wherein the researcher can participate in the change and continue to evaluate the process. First a variable is identified, a course of action is defined, and then the issue is monitored for continuous evaluation. Action research composes of a cycle of steps composed of planning, action, fact-finding, and reflection. The immediate response from the scenario can be verified after each action is carried out [6] [9].

In the study, the researcher participated in the actual process of policy formulation and platform establishment, using interviews and observation to collect comprehensive data, and interacting with related parties, to examine the process of promoting cloud computing industry development and the analysis of relevant problems in government, employing actual participation and continuing improvement to explore these issues. As shown in Figure 1, this paper is an action research from the perspective of an aide of the Cloud Computing Project Management Office and investigates the implementation and challenges of the Cloud Computing Development Project and Cloud Computing Application and Development Project, wherein the discussion stems from actual participation and improvements made to the projects [1].

\section{A. Cloud Computing Development Project}

In 2009, the Taiwanese government positioned cloud computing as a key strategic industry the development of which needed to be prioritized. This was followed in 2010 by the launching of the Cloud Computing Development Project, which sought to use cloud computing to link together the IT hardware, software and information services segments within Taiwan's ICT sector through a total of 15 cloud computing development applications.

\section{B. Cloud Computing Application and Development Project}

In 2012, responding to changes in market demand and intensified international competition in terms of technology, etc., the overall strategic direction and objectives of the Cloud Computing Development Project were revised to emphasize value creation and production value, and the Project was renamed the Cloud Computing Application and Development Project, shown in Table 1. It was anticipated that, through the development of public-sector cloud computing applications, it would be possible to stimulate the continued development of Taiwan's cloud computing industry, while also planning the establishment of cloud computing service platforms to serve as matching mechanisms for supply and demand.

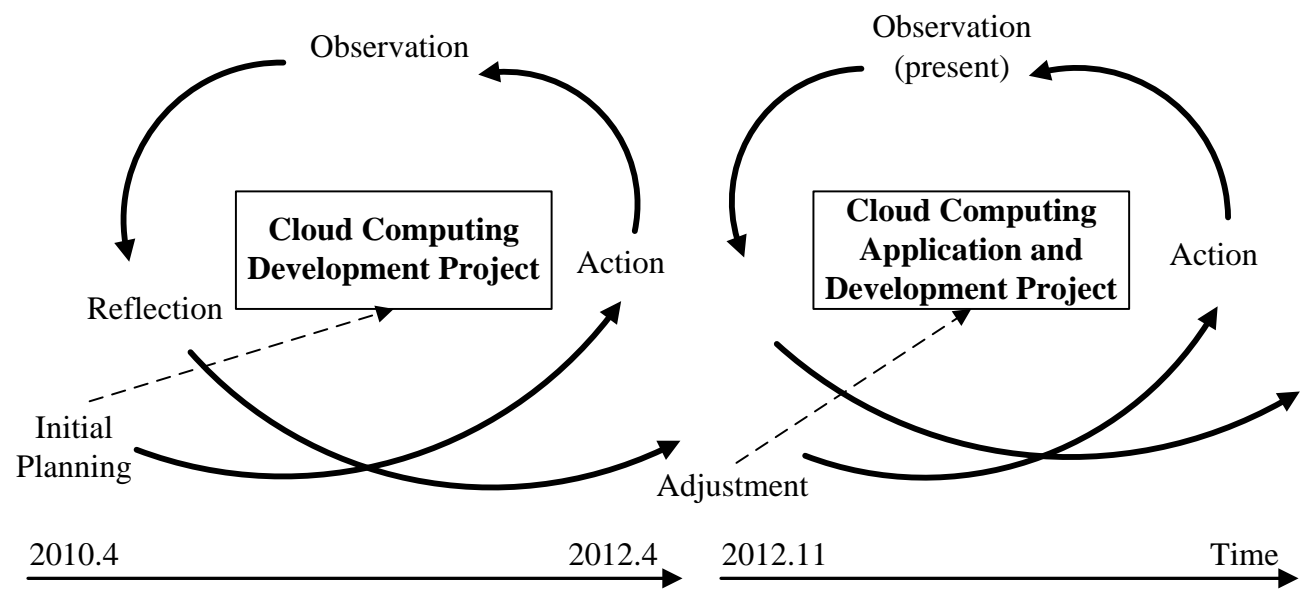

Fig. 1. Action Research Process 
TABLE I. The ANALYSIS OF Policy Evolution IN TAIWAN

\begin{tabular}{|c|c|c|}
\hline & Cloud Computing Development Project & Cloud Computing Application and Development Project \\
\hline Period & 3.5 years $(2009.4-2012.10)$ & 1.5 years (2012.11-present) \\
\hline Target & $\mathrm{G} 2 \mathrm{~B}, \mathrm{~B} 2 \mathrm{~B}$ & $\mathrm{G} 2 \mathrm{~B}, \mathrm{~B} 2 \mathrm{~B}, \mathrm{G} 2 \mathrm{C}$ \\
\hline Strategy & $\begin{array}{l}\text { - Develop advanced technology and } \\
\text { infrastructure } \\
\text { - Popularize concepts and demonstrate new } \\
\text { applications }\end{array}$ & $\begin{array}{l}\text { - } \\
\text { - } \text { Build the foundation for the system software } \\
\text { - } \\
\text { - } \\
\text { - } \\
\text { - } \\
\end{array}$ \\
\hline Framework & $\begin{array}{l}\text { - Governance: Committee and PMO established } \\
\text { - Supply: Leverage C4(cloud, connectivity, } \\
\text { commerce, client) industry chain } \\
\text { - Demand: e-Government to new G-Cloud ideas }\end{array}$ & $\begin{array}{l}\text { - Dual focus (application \& industry) and bridging by } \\
\text { PMO } \\
\text { - Supply: technology and promotion } \\
\text { - Demand: roll-out unqualified G-Cloud targets }\end{array}$ \\
\hline IT artifact supported & N/A & Cloud Open Lab for matchmaking \\
\hline Application Outcomes & $\begin{array}{l}\text { - } 3 \text { specifics areas } \\
\text { - } 10 \text { applications }\end{array}$ & $\begin{array}{l}\text { - } 5 \text { specifics areas } \\
\text { - } 10 \text { applications }\end{array}$ \\
\hline
\end{tabular}

With the developments taking place in cloud computing technology, the allocation of resources by both the government and the private sector to cloud computing technology development - including collaboration between Taiwanese corporations and research institutes to develop cloud computing application platforms, building on existing IT hardware to design and develop innovative new cloud computing applications - will drive the development of the cloud computing sector and the environment that supports it; at the same time, as more Taiwanese firms begin to develop overseas markets for cloud computing applications, these initiatives will contribute to the continued growth of the Taiwanese economy as a whole [10].

\section{A Key Role: PMO}

The main functions of Cloud Computing Project Management Office are to help domestic companies participate in government projects, link the cloud computing industry and government application services together, and carry out the inter-ministerial integration of services to businesses and the people as well as the use of government resources. The office provides technical and administrative leadership to cloud computing initiatives. The Cloud Computing Project Management Office proposed the revised project structure to address the international market demands and technical competition. The Cloud Computing Development Project has undergone a constant roll-out process after its introduction in 2010, with a series of revisions aimed at adjusting the project accordingly for continued innovation and matching government policy to industry needs.

Initially, the revision called for attention to the supply, demand, and administrative aspects of the previous projects to propose the two major adjustment policies. The first is to improve the supply and demand through 5 major policies: "Promote the valuable applications for citizens," "Build the foundation for the system software," "Energy efficiency," "Develop the expertise for applications," and "Leverage local infrastructure" to promote the relevant practices.
The second is to strengthen the governing policy and secure the mechanism for promoting supply and demand by adding the additional concept of supply-demand matching as provided by the Cloud Open Lab. The government shall lead the industry with official policies, to truly expand and develop the cloud industry in Taiwan. Based on the two major policies, the structure of the project is revised with the following three key focuses:

\section{A. Dual-focus triple-stage framework}

The template is designed so that author affiliations are not repeated each time for multiple authors of the same affiliation. Please keep your affiliations as succinct as possible (for example, do not differentiate among departments of the same organization). This template was designed for two affiliations.

1) Develop a strategy: Develop the 5 major driving policies based on the project guidelines.

2) Plan an evaluation policy: Develop the evaluation policy based on the cloud computing guidelines.

3) Agency integration project: Integrate the agency development projects with key focus on government applications.

\section{B. Triple-stage process for establishing the supply-demand matching platform}

Implement the Cloud Open Lab supply-demand matching service:

1) Planning and implementation of the platform: Energize the IT vendors of Taiwan through the government cloud applications, to verify, validate, and certify the supply and demand scenario.

2) Collect industry solutions: Provide a channel for business opportunities and create cloud solutions developed locally in Taiwan.

3) Government promotion and explanations: One-stop service to reduce initial cost of the cloud application. 


\section{Leading with triple-stage government application}

Government applications to lead industry development and demonstrate the performance to the public:

1) Cross-agency communication and coordination: Government agencies are invited to develop a solution and strategy, and reach a consensus for the project.

2) Assist agencies in the project proposal: Government agencies are invited and give counseling for project proposals.

3) Planning, evaluation, and integration: The proposed projects from all agencies are evaluated.

\section{RESULT}

With the two major adjustment directions and three key areas of focus, the various items of the Cloud Computing
Application and Development Project can be revised individually. This leads to a new wave of development for cloud computing in government applications and creates an industry roadmap in Taiwan. The performance and value created by the project can be investigated from two aspects:

\section{A. Dual-focus revised cloud computing project for multi-fold advantages}

The Cloud Computing Application and Development Project approved by the Executive Yuan shall focus on the dual-focus framework of "Government applications" and "Industry development." The "technical value" and "social value" shall also highlight the innovative value of cloud computing, thus the driving force and strategy behind the industry development shall be government applications.

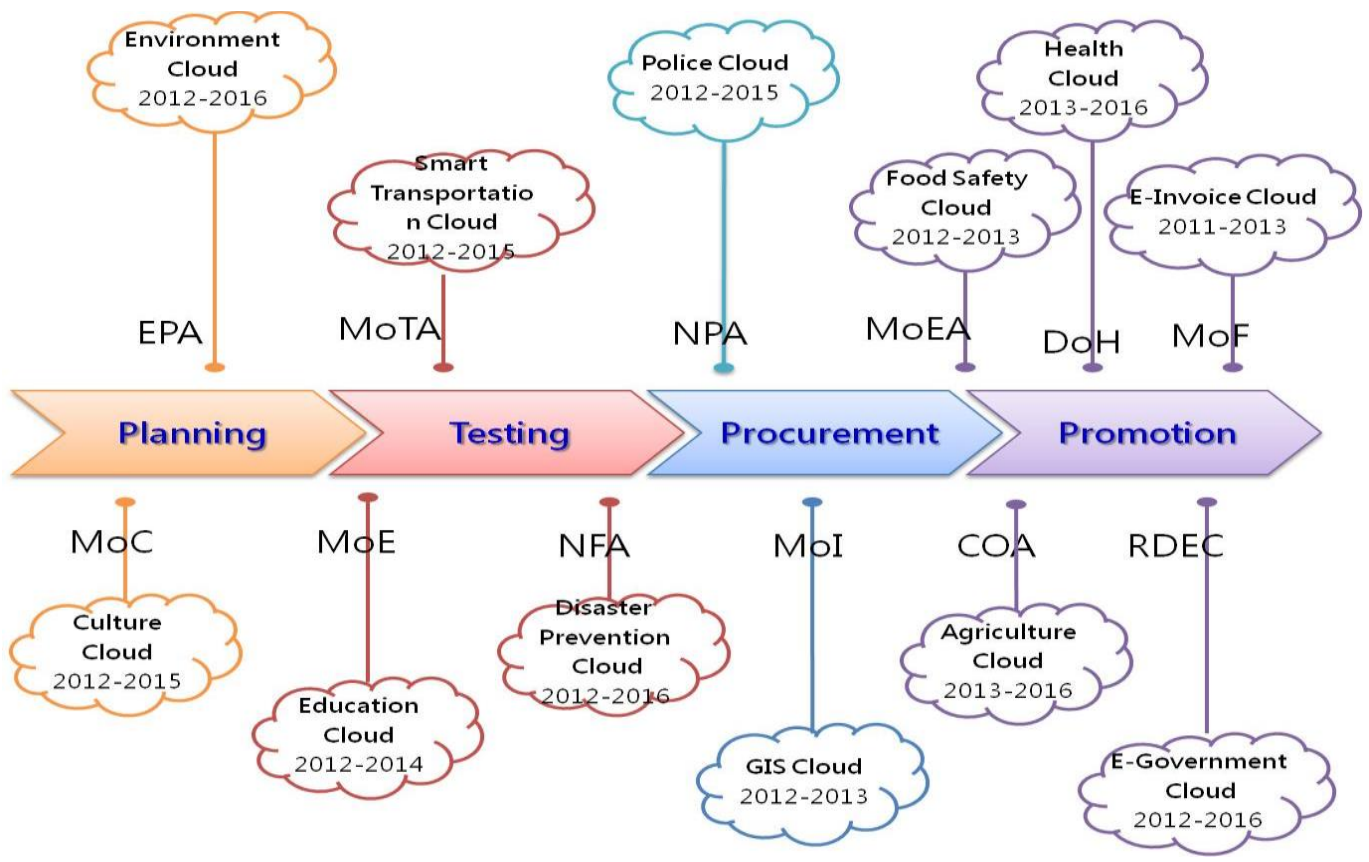

Fig. 2. Development Status of Taiwan Government Cloud

Government agencies shall be invited to discuss the 5 specifics areas of "Food and health safety," "Police and traffic," "Environmental resources and hazard prevention," "Education and culture," and "Public infrastructure" government applications. As shown in Figure 2 and Table 2, a target of 10 government applications shall be made available to the general public, with a target of 10 million people served by the government cloud services.

\section{B. Cloud Open Lab for supply-demand matching}

The Cloud Open Lab is a centralized hub for cloud solutions that provides supply-demand matching services, promotes industry R\&D efforts, and links government applications to the industry services. IT venders of Taiwan are strengthened by the demand driven by the government cloud services. The Cloud Open Lab developed brings together a variety of different cloud-based solutions to reduce search costs for private-sector firms and implement open purchasing standards; it provides commercialization environment resources and testing opportunities so that firms can implement service feasibility testing in advance, thereby reducing unnecessary hardware procurement and development costs, and increasing the probability than any given development project will be a success. The main functions of the platform, shown in Figure 3, are as follows:

1) Proof-of-concept (POC): Recruiting private-sector firms' existing cloud computing resources (supply side) to target particular cloud-based applications (demand side), providing matching and preliminary concept feasibility verification testing service.

2) Verification: Providing verification testing services for cloud-based applications (demand side) that verify the special features of these applications; providing verification testing services for cloud-based service level agreements (supply side) that verify conformity with openness criteria.

3) Certification: Providing certification and testing services, involving formal, signed documentation and/or marks or logos, in accordance with relevant cloud computing standards and rules. 
TABLE II. SUMMARY OF TAIWAN GOVERNMENT CLOUD

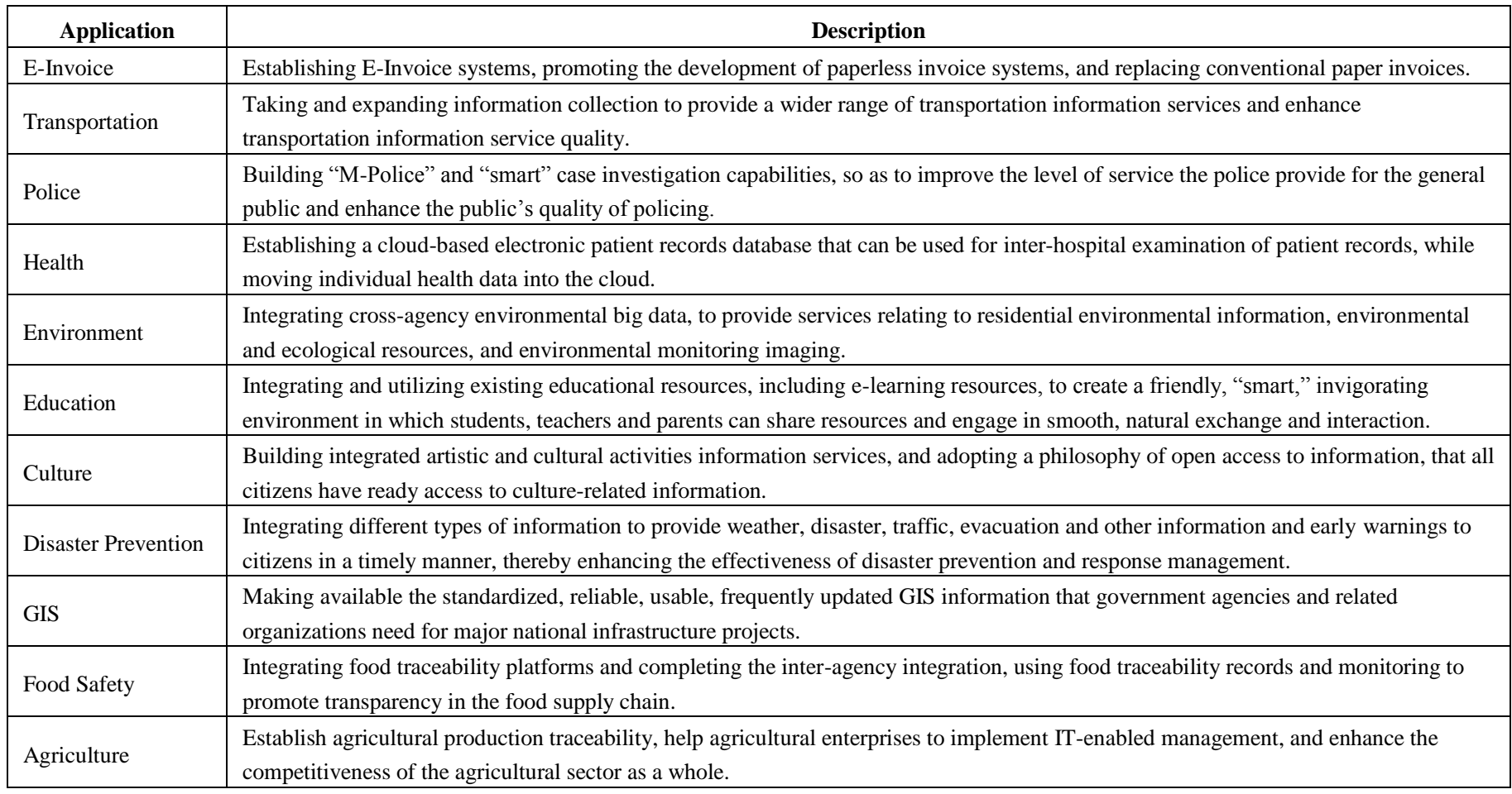

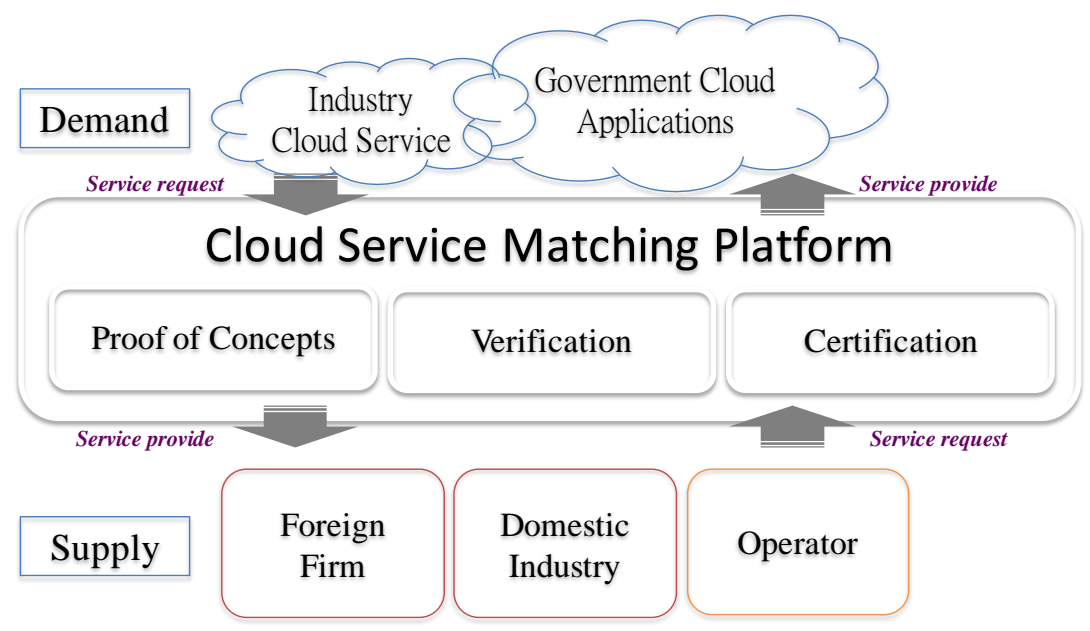

Fig. 3. Cloud Open Lab- A Connecting Bridge to Government and Enterprises

The Cloud Open Lab is a centralized resource for the industry that provides a training ground for driving R\&D to discover new markets for the cloud computing industry of Taiwan. There are currently over 80 vendors in the Cloud Open Lab, with over 142 products on market shelves today. In terms of demand, the goal is to provide a one-stop service to reduce initial cost of the cloud application.

Government agencies shall be able to take advantage of the Cloud Open Lab to bridge the matching services and help test the government applications. Initially, a total of 9 agencies have joined the platform to trial run the government cloud applications on the vendor's products.

\section{CONCLUSION}

With a first-class network environment, IT environment and IT hardware manufacturing sector, Taiwan is well-placed to develop cloud computing. The overall level of IT hardware manufacturing technology in Taiwan is extremely advanced, the broadband Internet access penetration rate is high, and a high percentage of Taiwanese business enterprises have achieved an impressive level of e-enablement.

Both the Cloud Computing Development Project and Cloud Computing Application and Development Project, the cloud computing strategy roadmap, outline the implementation of cloud computing in Taiwan to create a smart lifestyle and 
kickstart the nation onto the path of becoming a technological powerhouse. The cloud industry has received strong official support with the government setting the pace for private investment and vendor to follow with the proprietary cloud computing infrastructure as the model platform. In accordance with the development strategy, the Cloud Computing Project Management Office is assisting vendors in participation of the government project to accelerate the development of the industry chain and launch e-government cloud services. The office, as a key role, is responsible for the planning and development of the cloud computing industry through comprehensive coordination, control, and execution. The office is tasked with assisting vendors in the investment and development of the government and corporate cloud services, thus boosting industry value and investment capacity in cloud computing applications.

\section{FURTHER RESEARCH}

Looking to the future, the office shall focus open data, government procurement and broadband infrastructure, to undertake planning for various cloud-based government services and encourage hardware manufacturers and software providers to from strategic alliances to pursue innovation, to promote the development of an ever wider range of cloudbased applications, and to re-engineer and streamline administrative procedures at all levels of government for better efficiency and transparency.

Most G-Clouds have moved to continuous improvement stage, some are still in the planning stage. Further researches can discuss obstacles and enablers of G-Cloud development, and the key factors to link the government and industry. From different G-Clouds and industry solutions development, researchers can offer various views to the cloud computing policy forming and implementation by the ethnographic research method.

\section{ACKNOWLEDGMENT}

The paper is, executed by Institute for Information Industry (III), supported by Ministry of Economic Affairs (MOEA), Taiwan. The author of this research, acting as a policy drafting staff, is involved in the progress of the cloud computing policy development in Taiwan (since 2010 - present).

\section{REFERENCES}

[1] Chen S. C., "The Evolution of Taiwan Cloud Computing Policy: An Action Research," The Proceeding of 2014 International Conference on e-Commerce, e-Administration, e-Society, e-Education, and eTechnology (e-CASE \& e-Tech 2014), pp. 483-489, April 2014.

[2] Daryl C. P., David M. S., Thomas J. B., David W. C., David J. C., Donna S., Rakesh K., Bruce R., "Five Refining Attributes of Public and Private Cloud Computing," Gartner Research, 2009.

[3] Elliott, J., Action Research for Educational Change, Open University Press, Milton Keynes, 1991.

[4] Fang L., Jin T., Jian M., Robert B., John M., Lee B., Dawn L., "NISTSP 500-292: NIST Cloud Computing Reference Architecture," National Institute Standards and Technology, 2011.

[5] Frank E. G., Christopher M., Ellen D., Christina L., "How to Message Cloud Offerings and Not Get Lost In the Fog," Forrester Research Inc, 2009.

[6] Kemmis, S., and Mctaggart, R., The Action Research Planner (3rd), Deakin University Press, Victoria, Australia, 1997.

[7] Lewin, K., "Action research and minority problems," Journal of Social Issues, Vol. 2, No. 1, pp. 34-46, 1946.

[8] Michael H., Fang L., Annie S., Jin T., "NIST-SP 500-291: NIST Cloud Computing Standards Roadmap," National Institute Standards and Technology, 2011.

[9] Wadsworth, Y., "What is Participatory Action Research?" Action Research International, Paper No.2. (website available at http://www.scu.edu.au/schools/gcm/ar/ari/p-ywadsworth98.html), 1998.

[10] Wu, C.C. and Chen S. C., "Migrating to the Cloud- A Review and Prospect of Taiwan ICT Vendors to Cloud Computing Market," Proceedings of the 19th Conference on Information Management \& Practice (IMP 2013), pp. 367-381, November 2013. 